\title{
Analysis Study of Solar Tower Power Plant \& Its Configuration Effects on Its Performance in Iraq (Baghdad City)
}

\author{
Mohammed H. Ali ${ }^{1}$ \\ ${ }^{1}$ College of Engineering, Al-Mustansiriya University, Baghdad, Iraq \\ Correspondence: Mohammed H. Ali, College of Engineering, Al-Mustansiriya University, Baghdad, Iraq. E-mail: \\ eng_mohamad951@yahoo.com
}

Received: December 12, 2012

Accepted: March 12, 2013 Online Published: March 20, 2013

doi:10.5539/mas.v7n4p55

URL: http://dx.doi.org/10.5539/mas.v7n4p55

\begin{abstract}
A solar chimney power plant model, consisting of a solar collector to produce a hot air when the incident solar radiation hit it, a solar chimney and a wind turbine with generator was investigated in this study. The mathematical model as a tool was used to study and analyze the performance of the power plant for electrical production in Baghdad city of Iraq as a result a mathematical equation was obtained for the hot air outlet temperature from the collector as a function of collector's area and solar radiation. The Manzanares model was used in this study and the results obtained from the proposed model of solar tower, having the height $195 \mathrm{~m}$, diameter of $10 \mathrm{~m}$, and the solar collector diameter of $244 \mathrm{~m}$ were compared with the results obtained when the solar tower configuration is changed. The results indicate that the significant impact to improve the output power is by increasing the collector's diameter from $244 \mathrm{~m}$ to $300 \mathrm{~m}$. It is also found that output power is effectively dependent on the chimney's height, it yields moderate increasing in power output when the height is increased from $195 \mathrm{~m}$ to $300 \mathrm{~m}$, and the chimney's diameter has a lower impact on solar tower output power in comparison with the other configuration of solar tower when it increases from $10 \mathrm{~m}$ to $20 \mathrm{~m}$.
\end{abstract}

Keywords: solar tower, solar energy, chimney, collector, power output

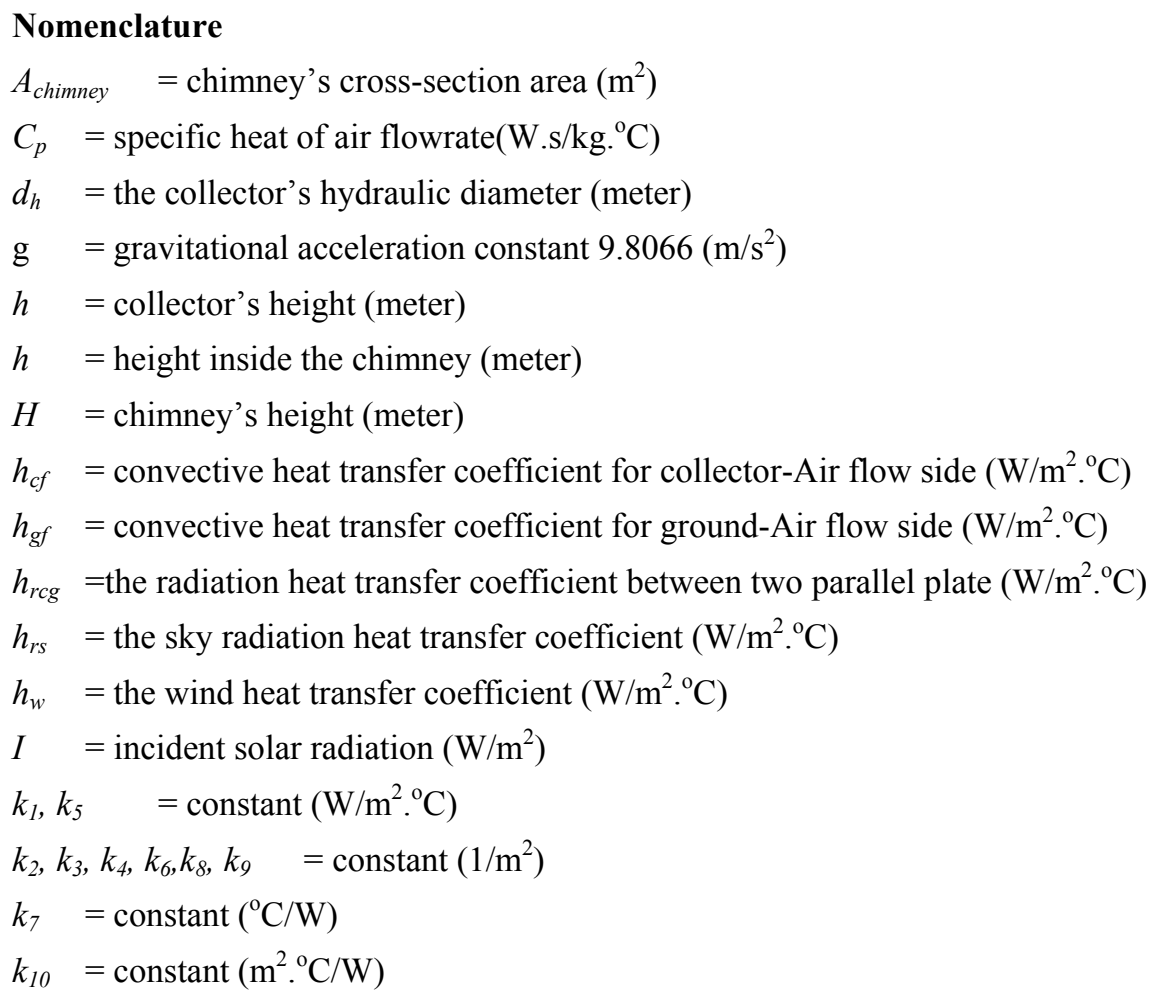


$k_{11}, k_{12}=$ constant (dimensionless)

$k_{f}=$ the air thermal conductivity $\left(\mathrm{W} / \mathrm{m} .{ }^{\circ} \mathrm{C}\right)$

$m$ = Air mass flow rate $(\mathrm{kg} / \mathrm{s})$

$P \quad=$ solar tower power output $(\mathrm{W})$

$r \quad=$ collector radius (meter)

$\mathrm{R} \quad=$ the maximum collector radius (meter)

$S_{I} \quad=$ the radiation heat flux absorbed by the collector cover $\left(\mathrm{W} / \mathrm{m}^{2}\right)$

$S_{2} \quad=$ the radiation heat flux absorbed by the ground soil $\left(\mathrm{W} / \mathrm{m}^{2}\right)$

$T=$ the temperature inside the chimney $\left({ }^{\circ} \mathrm{C}\right)$

$T_{a}=$ the ambient temperature $\left({ }^{\circ} \mathrm{C}\right)$

$T_{c}=$ collector cover temperature $\left({ }^{\circ} \mathrm{C}\right)$

$T_{f}=$ the airflow temperature $\left({ }^{\circ} \mathrm{C}\right)$

$T_{f 1}=$ the inlet airflow temperature $\left({ }^{\circ} \mathrm{C}\right)$

$T_{f 2}=$ the outlet airflow temperature $\left({ }^{\circ} \mathrm{C}\right)$

$T_{m}=$ the hot airflow mean temperature $\left({ }^{\circ} \mathrm{C}\right)$

$T_{g} \quad=$ the ground soil temperature $\left({ }^{\circ} \mathrm{C}\right)$

$T_{s} \quad=$ the sky temperature $\left({ }^{\circ} \mathrm{C}\right)$

$V_{\max }=$ the maximum air velocity inside chimney $(\mathrm{m} / \mathrm{s})$

$V_{\text {wind }}=$ wind speed $(\mathrm{m} / \mathrm{s})$

$U_{b}=$ the total ground heat loss coefficient $\left(\mathrm{W} / \mathrm{m}^{2} .{ }^{\circ} \mathrm{C}\right)$

$\Delta P_{\text {tot }}=$ the total pressure difference between the chimney base $\&$ the ambient $(\mathrm{Pa})$

$\Delta T_{12}=$ the temperature difference between collector's inlet and outlet temperatures $\left({ }^{\circ} \mathrm{C}\right)$

Greek symbols:

$\alpha=$ the thermal diffusivity $\left(\mathrm{m}^{2} / \mathrm{s}\right)$

$\alpha_{1}, \alpha_{2}=$ the collector and ground absorptivity

$B=$ the coefficient of volumetric thermal expansion $\left(1 /{ }^{\circ} \mathrm{C}\right)$

$\Gamma \quad=$ the temperature lapse of air flow in adiabatic chimney $\left({ }^{\circ} \mathrm{C} / \mathrm{m}\right)$

$\gamma_{a}=$ the temperature lapse of ambient air $\left({ }^{\circ} \mathrm{C} / \mathrm{m}\right)$

$\epsilon \quad=$ constant equal to 0.25

$\varepsilon_{c} \quad=$ emissivity of the collector

$\varepsilon_{g} \quad=$ emissivity of the ground soil

$\theta \quad=$ parameter represents a temperature $\left({ }^{\circ} \mathrm{C}\right)$

$\nu \quad=$ kinematic viscosity $\left(\mathrm{m}^{2} / \mathrm{s}\right)$

$\rho=$ the air density $\left(\mathrm{kg} / \mathrm{m}^{3}\right)$

$\Sigma=$ Stefan - Boltzmann constant equal to $5.6697 \times 10^{-8}\left(\mathrm{~W} / \mathrm{m}^{2} .{ }^{\circ} \mathrm{K}\right)$

$\tau_{l}=$ the collector cover transmissivity

Subscripts:

$1=$ collector's inlet

$2=$ collector's outlet

3 = chimney's inlet

$4=$ chimneys outlet 


\section{Introduction}

The crisis of the energy cost and its demand increases exponentially with fossil energy nearing exhaustion for present and future time as well as the environmental and air pollution are being more severe, so the strong demand to use or produce a new or renewable, clean and low cost energy is raised to confront this crisis.

This issue inspired the scientists to work hard to find the suitable sources for renewable energy that can contribute essentially to future energy need. There are many sources for those renewable energies, but the sun can be considered as the principle source of almost all kind of energy (Chaichan \& Kazem, 2011).

One of those methods is the Solar Chimney, which is operates as a hydroelectric power plant, but instead of water, it uses hot air which is useful in arid area (Mehla, Makade, \& Thakur, 2011).

The solar chimney is a power plant that uses:

1) The solar radiation to heat the large body of air inside the solar chimney's collector and raising the temperature of the air according to greenhouse effect under the transparent roof (collector's cover) which works primarily by preventing the absorbed heat from leaving the collector's structure through convection.

2) Due to the differences in temperature between the temperature at the base of the chimney and the atmosphere's temperature (ambient temperature), the air will draw continuously from the opened periphery's collector into the chimney due to the buoyancy effect.

3) A wind turbine or (turbines) can be mounted at the chimney's base in which the hot air pass over to convert part of the useful energy of the flowing air into electricity.

The solar chimney is a simple design; the idea was published in a magazine Electrical Energy by Isidoro Cabanyes in 1903, as a proposal for solar chimney. It is proposed by Schlaich in 1978. The project (the prototype tower) was built $150 \mathrm{~km}$ south of Madrid, in the town of Manzanares, it has been proven to work successfully producing $50 \mathrm{~kW}$ in 1982, producing energy for eight years.

The solar chimney, in general has the following characteristics:

1) It is a clean technology using renewable solar energy as a heat source which produces neither greenhouse effect gasses nor hazardous wastes.

2) It is able to absorb diffuse radiation when the weather is overcast with reduced power output.

3) The maintaining cost is too low and can be considered as a key advantage in areas that is sunny with a water shortage; it should not need cooling tower (Schlaich, Bdrgermann, Schiel, \& Weinrebe, 2005).

Recent studies related to solar chimney are mainly focused on large scale power plants with low cost and solar tower configuration for best efficiency and effective operation, whereas the previous studies have focused on the energy conservation performance, heat transfer and fluid flow in the solar chimney power system (Zhou,Yang, Xiaco, \& Shi, 2008). However, the temperature distribution along the collector radius and the mass variation with temperature change and its effect on the power generation has seldom reported.

\section{The Aim of This Paper}

In this paper a mathematical model for a simple solar tower is presented and validated with the proposal for Manzanares prototype, in order to have a theoretical formulating for temperature variation inside the collector and showing how the temperature change dominates on the mass flow rate of hot air moving through the collector. This analysis does not take into account the effect of ground (soil) storage that in fact is always existed for continuous production of energy also in absence of solar radiation in the night time (Cervone, Romito, \& Santini, 2011), it is limited to day sun shine time.

\section{Mathematical Analysis}

The solar tower analysis depends mainly on the following parameters which influence the power output of the solar tower as shown in Figure 1:

1) The ambient conditions which are represented by the solar insolation, ambient temperature and the wind velocity.

2) The solar tower configuration which are represented by the dimension of the chimney and the collector the chimney height $\mathrm{H}$, the chimney diameter $\mathrm{D}$, the collector radius $\mathrm{R}$ and the collector's periphery height $\mathrm{h}$.

The mathematical model of the solar chimney has been developed based on energy balance under the following assumptions: 
1) The performance of the power plant is analyzed at steady state flow (Direcksataporn, 2008), because solar radiation is transient in nature.

2) The collector cover temperature and the ground temperature don't change along the collector radius r, i.e. $d / d r$ for Tc and Tg is zero.

3) Air is an ideal gas and the flow is incompressible across the chimney since Mach number is below 0.3 (Hamdan, 2011).

4) The heat radiated to the chimney is ignored since the surface area of the collector is much larger than the surface area of the chimney. Therefore, heat transfer equation is considered for the collector (Hamdan, 2011).

5) The air flow in the system is due to buoyancy force in solar chimney (Zhou, Yang, Xiaco, \&Shi, 2008).

6) The flow in the collector is considered as a flow between two parallel plates (Bernardes \& Weinrebe, 2003).

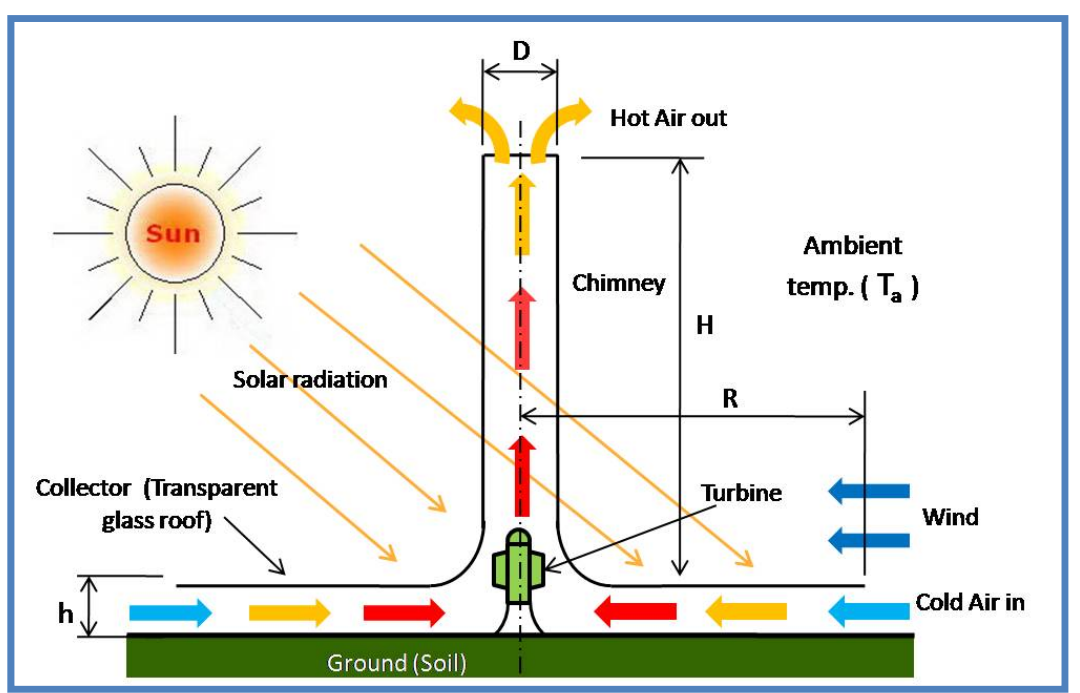

Figure 1. Solar Tower Schematic drawing showing the ambient condition and tower configuration

\subsection{Collector}

In this paragraph, the analysis of temperature rise in the collector part is determined. The formulating equation for the air stream along the collector's radius $r$ will be derived below using simple energy balance. The collector's cover (the transparent glass roof) receives its heat from the incident solar flux during the daylight time, heats up and transfer part of it to strike the ground soil. The ground absorbs this energy, heats up and transfer part of the solar energy to air flowing passing through the cavity between the cover and the ground by convection. The heat balance equations govern the collector's components are, see Figures 2 and 3:

For the collector's cover (the transparent glass), the energy balance equation is:

$$
\begin{aligned}
S_{1} & =h_{w}\left(T_{c}-T_{a}\right)+h_{r s}\left(T_{c}-T_{s}\right)+h_{c f}\left(T_{c}-T_{f}\right)+h_{r c g}\left(T_{c}-T_{g}\right)-h_{c f} \cdot T_{f}-h_{r c g} \cdot T_{g}+k_{l} \cdot T_{c} \\
& =S_{1}+h_{w} T_{a}+h_{r s} T_{s}
\end{aligned}
$$

Where, the radiation heat transfer coefficient between two parallel plates hrcg is (Bilgen \& Rheault, 2005):

$$
h_{r c g}=\frac{\sigma\left(T_{c}^{2}+T_{g}^{2}\right)\left(T_{c}+T_{g}\right)}{\left[\frac{1}{\varepsilon_{c}}+\frac{1}{\varepsilon_{g}}-1\right]}
$$

The solar radiation heat flux absorbed by the collector's cover (glass roof) is:

$$
S_{1}=\alpha_{1} I
$$

The sky temperature Ts is (Xinping et al., 2010): 


$$
T_{s}=0.0552 T_{a}^{1.5}
$$

The sky radiation heat transfer coefficient hrs is (Bernardes \& Weinrebe, 2003):

$$
h_{r s}=\frac{\sigma \varepsilon_{c}\left(T_{c}^{2}+T_{s}^{2}\right)\left(T_{c}+T_{s}\right)\left(T_{c}-T_{s}\right)}{\left(T_{c}-T_{a}\right)}
$$

The wind convection heat transfer hw is (Annaratone, 2010):

$$
\begin{gathered}
h_{w}=5.47+3.95 V_{\text {wind }} \\
k_{l}=h_{w}+h_{r s}+h_{c f}+h_{r c g}
\end{gathered}
$$

For the airflow in the colllector, the energy balance equation is:

$$
\begin{gathered}
m C_{p} d T_{f}=h_{c f}(2 \pi r d r)\left(T_{c}-T_{f}\right)-h_{g f}(2 \pi r d r)\left(T_{f}-T_{g}\right) \\
\frac{d T_{f}}{d r}=k_{2}(2 \pi r)\left(T_{c}-T_{f}\right)-k_{3}(2 \pi r)\left(T_{f}-T_{g}\right) \\
\left(\frac{d}{d r}+(2 \pi r) k_{4}\right) T_{f}-(2 \pi r) k_{3} T_{g}-(2 \pi r) k_{2} T_{c}=0
\end{gathered}
$$

Where: $k_{2}=\frac{h_{c f}}{m C_{p}}, k_{2}=\frac{h_{g f}}{m C_{p}}, k_{4}=k_{2}+k_{3}$

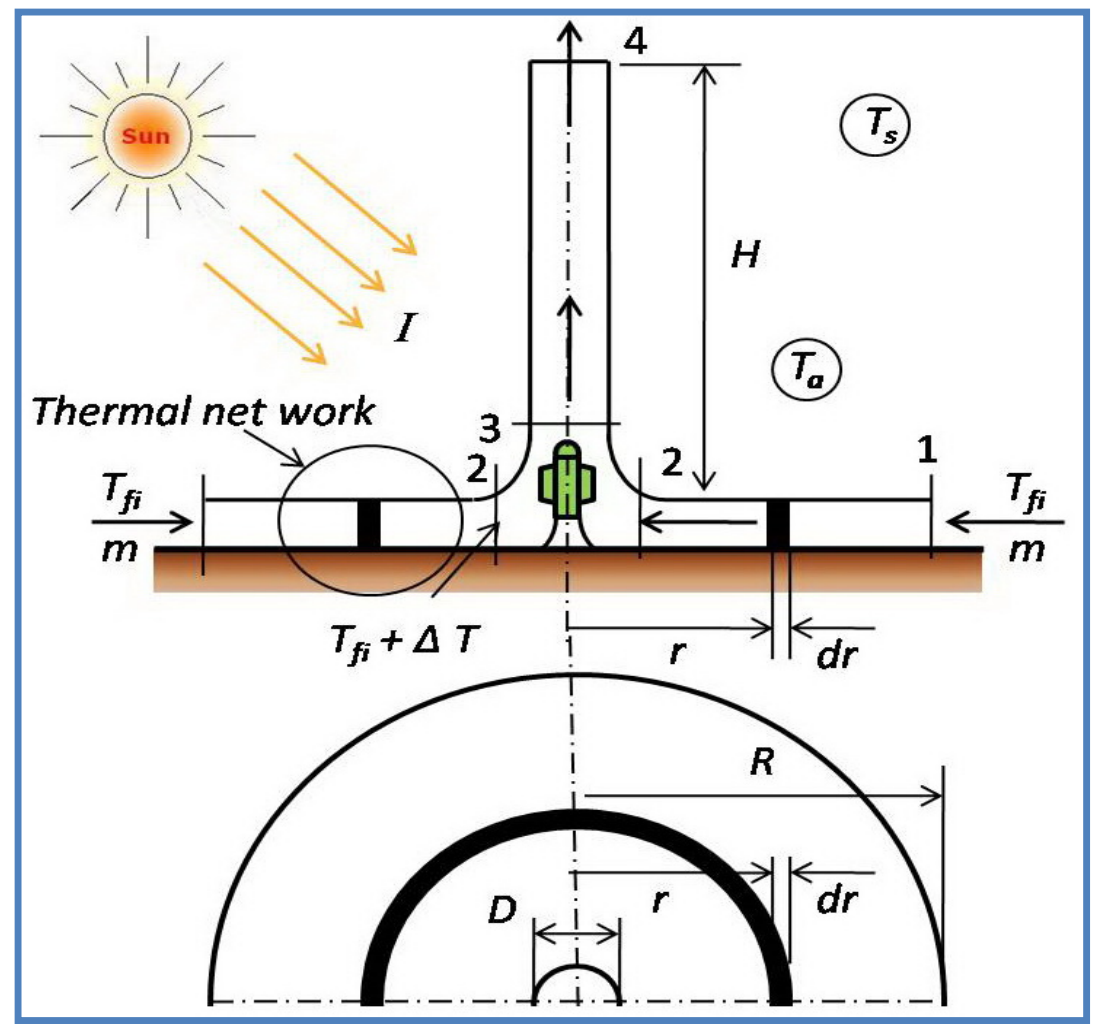

Figure 2. Schematic drawing of simplified solar tower for energy equations 


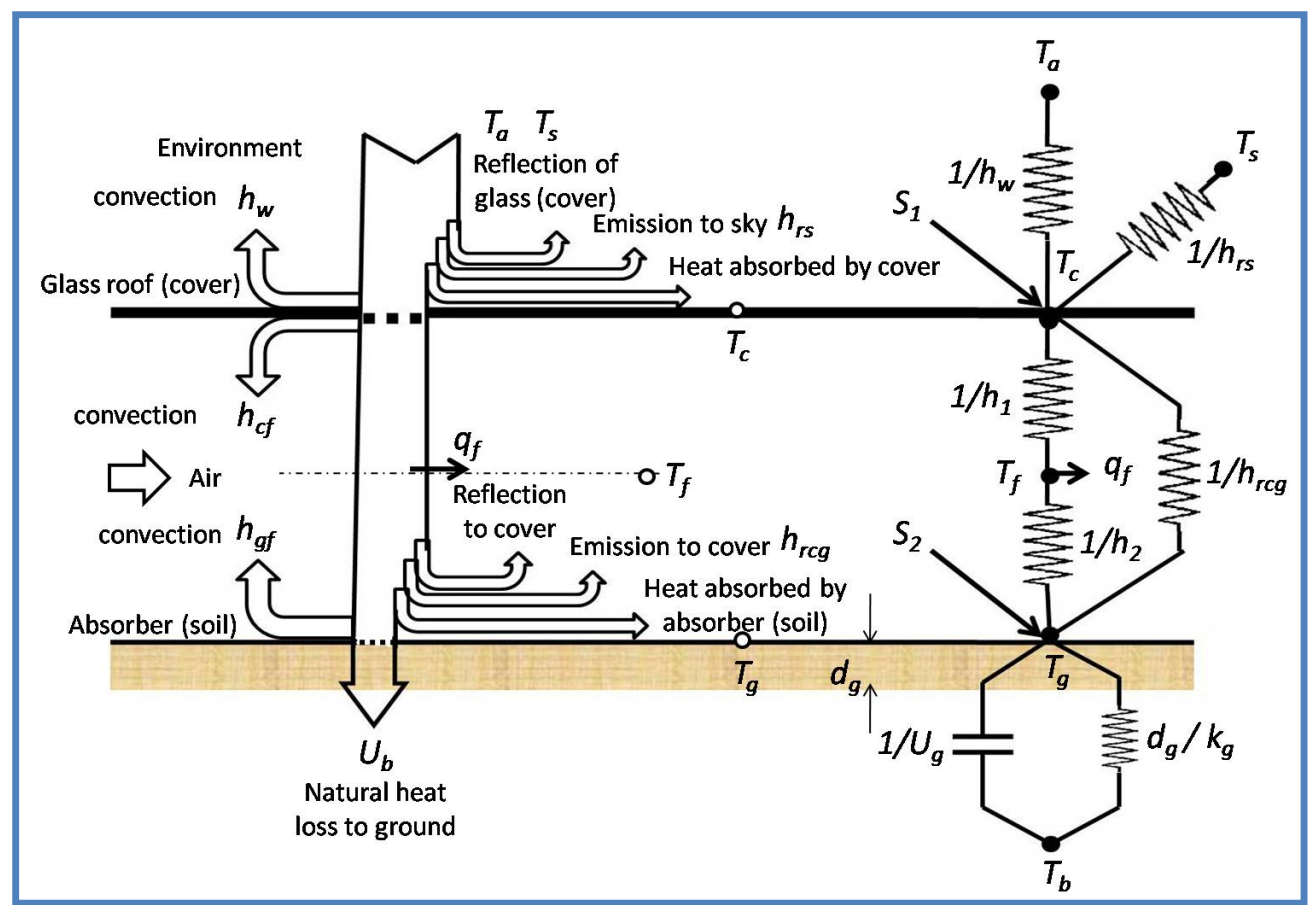

Figure 3. Thermal network for the collector of solar tower

The convective heat exchange between the cover and the air flow $h_{c f}$, and between the air flow and the ground $h_{g f}$ are considered equal, it can be calculated from the following equation (Chergui, Larbi, \& Bougdjar, 2011):

$$
\begin{gathered}
h_{c f}=h_{g f}=\frac{k_{f}}{d_{h}} N u_{m} \\
N u_{m}=0.54 R a^{0.25}, \text { for } 2 * 10^{4}<R a<8 * 10^{7} \\
N u_{m}=0.15 R a^{0.33} \text { for } 8 * 10^{7}<R a<8 * 10^{11}
\end{gathered}
$$

The collector has a circular shape with radius $R$ and height $h$, thus the hydraulic diameter is equal to (Chergui, Larbi, \& Bougdjar, 2011):

$$
d_{h}=\frac{4\left(2 \pi R^{*} h\right)}{2(2 \pi R+h)} \cong 2 h
$$

The Rayleigh number $R a$ is defined as the product of the Grashof $G r$ and $P r$ numbers and is equal to (Bahrami, 2011):

$$
R a=\operatorname{Gr} P r=\frac{g \beta\left(T_{g}-T_{f}\right) d_{h}^{3}}{v^{2}} \operatorname{Pr}
$$

$\beta$ is the coefficient of volumetric thermal expansion, it is equal to (Bilgen \& Rheault, 2005):

$$
\beta=\frac{1}{T_{f m}}
$$

$T_{f m}$ is the mean temperature of the hot air, can be given as (Direcksataporn, 2008):

$$
T_{f m}=\epsilon T_{a}+(1-\epsilon) T_{f 2}
$$

$\epsilon$ is a constant and should be equal to 0.25 for temperature approximation $T_{f m}$ where the air properties should be evaluated. $T_{f 2}$ is the air outlet temperature from the collector at section 2.

For the ground (soil) in the colllector, the energy balance equation is: 


$$
S_{2}+h_{g f}\left(T_{f}-T_{g}\right)+h_{r c g}\left(T_{c}-T_{g}\right)=U_{b}\left(T_{g}-T_{b}\right)-h_{g f} T_{f}+k_{5} T_{g}-h_{r c g} T_{c}=S_{2}+U_{b} T_{a}
$$

Where: $k_{5}=h_{g f}+h_{r c g}+U_{b}$

$\mathrm{Ub}$ the total ground heat loss coefficient is given by (Xinping et al., 2010):

$$
U_{b}=\frac{1}{\frac{d_{g}}{k_{g}}+\frac{1}{U_{g}}}
$$

$k_{g}$ is the thermal conductivity of ground bed. $d_{g}$ is the damping depth, which dictates the extent of temperature variation meter is given by (Storage, 2005):

$$
d_{g}=\sqrt{\frac{2 \alpha}{\omega}}
$$

$\alpha$ is the ground (soil) thermal diffusivity, $\omega$ is the diurnal angular frequency which is equal to $0.0000727 \mathrm{~s}^{-1}$ (Storage, 2005) and given by:

$$
\omega=\frac{2 \pi}{t}
$$

$U_{g}$ the ground heat transfer coefficient is given by (Xinping et al., 2010):

$$
U_{g}=2 \sqrt{\frac{k_{g} \rho_{g} C_{p g}}{\pi t}}
$$

In this model, a mean value for a period t of 84600 second is used in the energy calculation in a day and $T_{b}$ is equal to $T_{a}$ (Xinping et al., 2010).

The solar radiation heat flux absorbed by the ground is:

$$
S_{2}=\tau_{1} \alpha_{2} I
$$

The transmittance and the Absorptivity of the collector cover (glass roof) is (Bernardes \& Weinrebe, 2003):

$$
\tau_{1} \cong \tau_{a} \tau_{r}
$$

$\tau_{a}$ is transmittance considering only absorption losses, and $\tau_{r}$ is transmittance of initially unpolarized radiation.

The Equations 1, 2 and 3 can be written in the matrix form as follows:

$$
\left[\begin{array}{ccc}
-h_{c f} & -h_{r c g} & k_{1} \\
\left(\frac{d}{d r}+(2 \pi r) k_{4}\right) & -(2 \pi r) k_{3}-(2 \pi r) k_{2} \\
-h_{c f} & k_{5} & -h_{r c g}
\end{array}\right]\left[\begin{array}{l}
T_{f} \\
T_{g} \\
T_{c}
\end{array}\right]=\left[\begin{array}{c}
S_{1}+h_{w} T_{a}+h_{r s} T_{s} \\
0 \\
S_{2}+U_{b}
\end{array}\right]
$$

The above equation can generally be written as:

$$
[A][T]=[B]
$$

And, the temperature vector can be determined by matrix inversion as follows:

$$
[T]=[A]^{-1}[B]
$$

On this basis, Equation 4 can be solved for the air flow temperature $T_{f}$ to yield the following equation:

$$
\frac{d T_{f}}{d r}=(2 \pi r) k_{6}\left(k_{10} I-T_{f}+k_{11} T_{a}+k_{12} T_{s}\right)
$$

Where: 


$$
\begin{gathered}
k_{6}=\frac{k_{1}\left(k_{4} k_{5}-h_{g f} k_{3}\right)-h_{r c g}\left(h_{g f} k_{2}+h_{r c g} k_{4}+h_{c f} k_{3}\right)-h_{c f} k_{2} k_{5}}{k_{1} k_{5}+h_{r c g}^{2}} \\
k_{7}=\frac{\left(h_{r c g} k_{3}+k_{2} k_{5}\right) \alpha_{1}+\left(h_{r c g} k_{2}+k_{1} k_{3}\right) \tau_{1} \alpha_{2}}{k_{1} k_{5}+h_{r c g}^{2}} \\
k_{8}=\frac{k_{2}\left(h_{r c g} U_{b}+h_{w} k_{5}\right)+k_{3}\left(h_{w} h_{r c g}+U_{b} k_{1}\right)}{k_{1} k_{5}+h_{r c g}^{2}} \\
k_{9}=\frac{h_{r c g}\left(h_{r c g} k_{3}+k_{2} k_{5}\right)}{k_{1} k_{5}+h_{r c g}^{2}} \\
k_{10}=\frac{k_{7}}{k_{6}}, k_{11}=\frac{k_{8}}{k_{6}}, k_{12}=\frac{k_{9}}{k_{6}}
\end{gathered}
$$

We can write Equation 5 with new parameter $(\theta)$ by letting:

$$
\theta=k_{10} I-T_{f}+k_{11} T_{a}+k_{12} T_{s}, \text { thus } \frac{d \theta}{d r}=-\frac{d T_{f}}{d r}
$$

Then, Equation 5 becomes:

$$
\frac{d \theta}{d r}+(2 \pi r) k_{6} \theta=0
$$

The solution of this equation is (WYLIE, 1966):

$$
\theta=C e^{-\int^{R}(2 \pi r) k_{6} d r}=C e^{-k_{6} \pi\left(R^{2}-r^{2}\right)}
$$

At $r=R, \theta=\theta_{i}$, thus the solution of Equation 7 becomes:

$$
\theta=\theta_{i} e^{-k_{6} \pi\left(R^{2}-r^{2}\right)}
$$

Substituting, $\theta=k_{10} I-T_{f}+k_{11} T_{a}+k_{12} T_{s}$ and $\theta_{i}=k_{10} I-T_{f i}+k_{11} T_{a}+k_{12} T_{s}$, we will obtain the final solution for Equation 7 becomes as follows:

$$
T_{f}=T_{f i} e^{-k_{6} \pi\left(R^{2}-r^{2}\right)}+\left(1-e^{-k_{6} \pi\left(R^{2}-r^{2}\right)}\right)\left(k_{10} I+k_{11} T_{a}+k_{12} T_{s}\right)
$$

\subsection{Chimney}

Referring to Figure 2, the function of chimney is to convert the thermal energy produced in the collector into a kinetic energy; it is determined by both the temperature rise of the ambient airflow from the collector inlet at 1 to the collector outlet at 2 and the height of the chimney. The pressure difference $\Delta P_{\text {tot }}$ which is produced due to the density difference between the airflow at chimney base 2 and at the chimney outlet 4 is calculated from the following equations (Zhou, Yang, Xiaco, \& Shi, 2008):

$$
\Delta P_{t o t}=0.00353 g H\left(\Delta T_{12}+\frac{\left(\gamma_{a}-\gamma\right) H}{2}\right)
$$

Pressure difference $\Delta P_{\text {tot }}$ is actually subdivided into static and dynamic component depending on the energy taking up by the turbine. Without turbine, a maximum flow speed is achieved and the whole pressure difference is used to accelerate the air and converted into kinetic energy (Schlaich, Bdrgermann, Schiel, \& Weinrebe, 2005). 
Thus the maximum chimney airflow rate can be reached and the maximum air velocity is expressed as (Zhou, Yang, Xiaco, \& Shi, 2008):

$$
V_{\max }=\sqrt{\frac{2 \Delta P_{t o t}}{\rho_{2}}}
$$

The maximum power is drawn when the chimney air flowrate velocity $V_{2}$ is one third of $\left(V_{\max }\right)$ in the case of turbine being on load (Zhou, Yang, Xiaco, \& Shi, 2008). From Equations 9 and 10, the velocity in the chimney $V_{2}$ can be expressed as:

$$
V_{2}=\frac{1}{3} \sqrt{\frac{2 \Delta P_{t o t}}{\rho_{2}}}=\frac{1}{3} \sqrt{\frac{0.00353 g H\left(2 \Delta T_{12}+H\left(\gamma_{a}-\gamma\right)\right)}{\rho_{2}}}
$$

Thus, the air mass flowrate of the hot air passing through the chimney can be calculated with the following equation (Zhou, Yang, Xiao, Hou, \& Xing, 2008):

$$
m=\rho_{2} \cdot A_{\text {chimney }} V_{2}
$$

The power output $\mathrm{P}$ of the solar tower can be calculated from the following equation (Schlaich, Bdrgermann, Schiel, \& Weinrebe, 2005):

$$
P=\frac{1}{2} m V_{\max }^{2}
$$

\section{Input for the Model}

The temperature output from the solar chimney's collector depends on many factors such as ambient conditions which are mentioned below, as well on solar chimney configurations which are represented by the solar chimney dimensions.

Daily solar radiations of direct and diffuse for clear sky day were calculated based on a mathematical models equations for horizontal surfaces for 1st of January and 3rd of August (Stine \& Gayer, 2001) for Baghdad City in

\begin{tabular}{|c|c|c|c|c|c|c|c|c|c|c|c|c|c|c|c|c|}
\hline \multicolumn{17}{|c|}{ Local Clock Time (LCT) (hour) } \\
\hline 4 & 5 & 6 & 7 & 8 & 9 & 10 & 11 & 12 & 13 & 14 & 15 & 16 & 17 & 18 & 19 & 20 \\
\hline \multicolumn{17}{|c|}{ Total solar flux incident on Horizontal wall facing south $\left(\mathrm{W} / \mathrm{m}^{2}\right)$} \\
\hline $\begin{array}{l}\text { 1st of } \\
\text { Jan. }\end{array}$ & & & 0 & 113 & 272 & 411 & 502 & 534 & 504 & 415 & 277 & 118 & 0 & & & \\
\hline $\begin{array}{l}\text { 3rd of } \\
\text { Aug. }\end{array}$ & 0 & 96 & 285 & 496 & 687 & 837 & 934 & 970 & 942 & 852 & 708 & 522 & 312 & 120 & 0 & \\
\hline \multicolumn{17}{|c|}{ Ambient Temperature $\left({ }^{\circ} \mathrm{C}\right)$} \\
\hline $\begin{array}{l}\text { 1st of } \\
\text { Jan. }\end{array}$ & 5.9 & 5.5 & 5 & 5.8 & 8.8 & 10 & 13.5 & 16 & 17 & 19.5 & 20.3 & 18.8 & 16.6 & 15.5 & 14.3 & \\
\hline $\begin{array}{l}\text { 3rd of } \\
\text { Aug. }\end{array}$ & 30 & 30 & 31.2 & 33 & 35.6 & 38 & 40.5 & 43.2 & 45 & 45.6 & 45.5 & 45.2 & 44.8 & 43.3 & 41.2 & \\
\hline
\end{tabular}
Iraq, and as well daily ambient temperature for the same days available for Baghdad city Iraq are used as simulation input, those values are tabulated in Table 1.

Table 1. The Total solar flux incident on horizontal surfaces and the ambient temperature for Baghdad city

In addition, the other parameters where used to simulate the calculation for the solar chimney power plant model "Manzanares model" are also tabulated in the following Table 2. 
Table 2. Parameters used in the power plant model

\begin{tabular}{lcc}
\hline Parameter & Value & Unit \\
\hline Chimney height & 195 & $\mathrm{~m}$ \\
Chimney diameter & 10 & $\mathrm{~m}$ \\
Collector diameter & 244 & $\mathrm{~m}$ \\
Collector height & 1.85 & $\mathrm{~m}$ \\
Cover material & Glass & - \\
Cover refractive index & 1.526 & - \\
Cover emissivity & 0.90 & - \\
Cover extinction coefficient & 23.6 & $\mathrm{~m}^{-1}$ \\
Absorber Absorptivity & 0.93 & - \\
Absorber emittance & 0.90 & - \\
Transmittance-absorptance product & 0.8 & - \\
Ground thermal conductivity & 0.6 & $\mathrm{~W} / \mathrm{m}^{-1} \cdot \mathrm{K}^{-1}$ \\
Ground thermal diffusivity & $2.91 \times 10^{-7}$ & $\mathrm{~m}^{2} \cdot \mathrm{s}^{-1}$ \\
Baghdad city Latitude & 33.35 & $\mathrm{deg}$ \\
Baghdad city Longitude & 44.416 & $\mathrm{deg}$ \\
\hline
\end{tabular}

\section{Results and Discussion}

In this paragraph, the analysis for this research shows the possibility to predict the temperature variation across the collector and the temperature rise from the inlet to outlet of the collector and showing the parameters that affect the temperature rise power output in solar chimney. The analysis can be carried out by assuming an initial air mass flowrate and an iterative process is used to commence the calculation for temperature rise through the chimney's collector.

For specific solar chimney, its configuration is fixed that means its dimensions are constant. Thus the initial guess of the mass flowrate inside the chimney can be estimated by using Equation 11, which it shows that $V_{2}$ is a function of $\Delta T_{12}$ only, and then by using Equation 12 the air mass flowrate can be calculated.

So a graph which shows the relation between the temperature rise and the mass flow rate inside the chimney can be drawn to facilitate the closest guess choice for the air mass flowrate to use in predicting the power output of the solar chimney and to see how the solar chimney configuration change effect the solar chimney performances.

Figure 4 shows the air mass flowrate change versus the temperature rise in solar chimney by using Equations 8 and 9 .

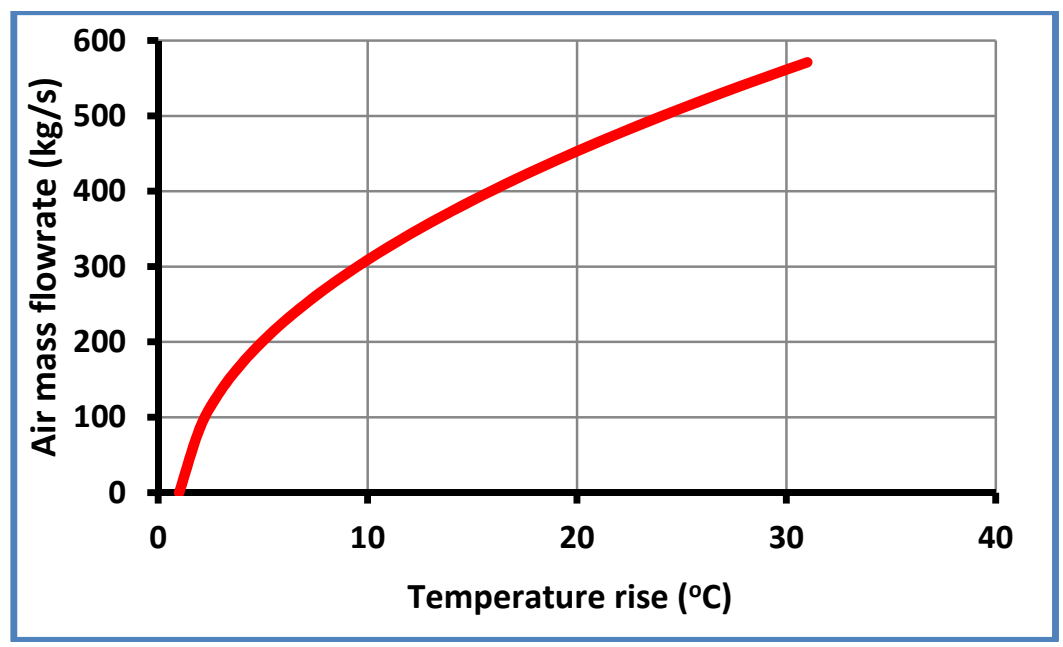

Figure 4 . The air mass flowrate variation with temperature rise in solar chimney's collector 
To guess the mass flowrate for each hour from the sunrise to sunset time Figure 4 is used for this purpose, and then in return the temperature outlet from the collector $T_{f}$ can be estimated with help of Equation 8 and compared with the corresponding temperature rise value of Figure 4 . If the difference between any corresponding new and old values is equal or less than the assumed acceptable difference of $\left(0.1^{\circ} \mathrm{C}\right)$, the iteration is stopped.

Figure 5 shows the temperature rise $\Delta T_{12}$ and the chimney velocity $V_{2}$ during the sun shine on 3rd of August, whereas Figure 6 shows them during the sun shine on 1st of January.

Those figures showed that the temperature rise is mainly proportional on the solar intensity $I$ and solar chimney configuration, but for specified solar tower the dimensions are fixed, so the parameters that affect the temperature rise are the solar intensity and the ambient temperature as it is clear from Equation 8.

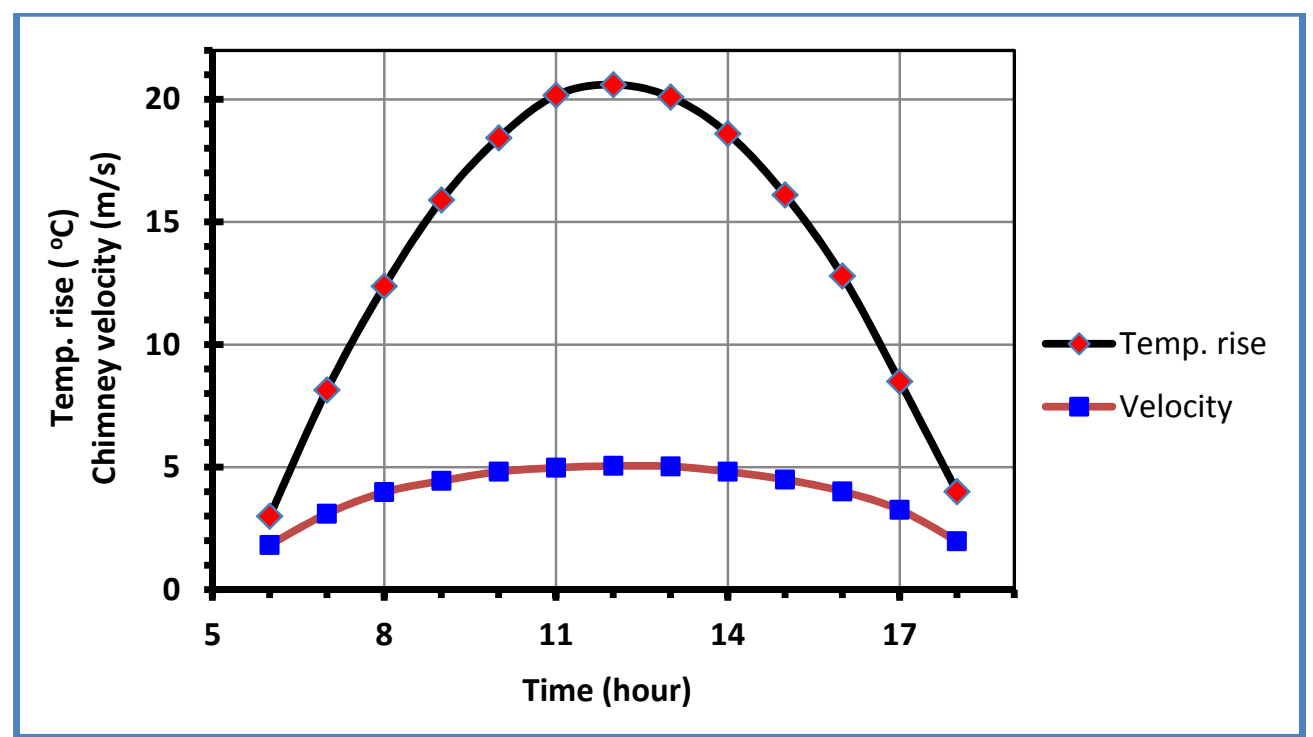

Figure 5. The temperature rise in solar collector \& chimney velocity during 3rd of August

As a result the velocity inside the chimney is also affected with these two parameters according to Equation 11, which it showed that $V_{2}$ is a function of $\Delta T_{12}$. It appears that temperature rise and chimney velocity in August is higher than in January due to higher solar intensity and ambient temperature.

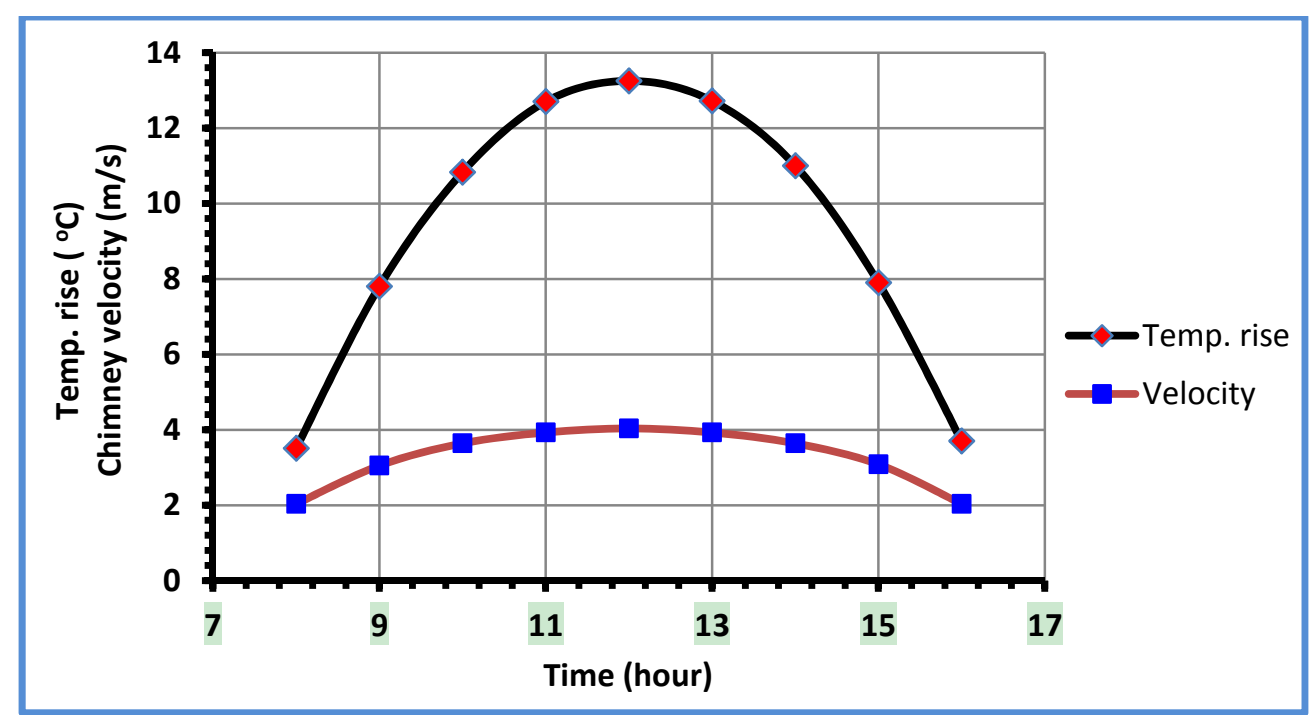

Figure 6 . The temperature rise in solar collector \& chimney velocity during 1 st of January 
Figure 7 shows the temperature variation of collector outlet temperature and the ambient temperature during the sun shine on 3rd of August, this temperature was obtained by using Equation 8. It appears that the solar intensity has a measurable impact on a thin skin of the ground soil, the ground first absorbs the solar heat, increasing its temperature $T_{g}$, then it initiated to re-emit the heat to air flowrate.

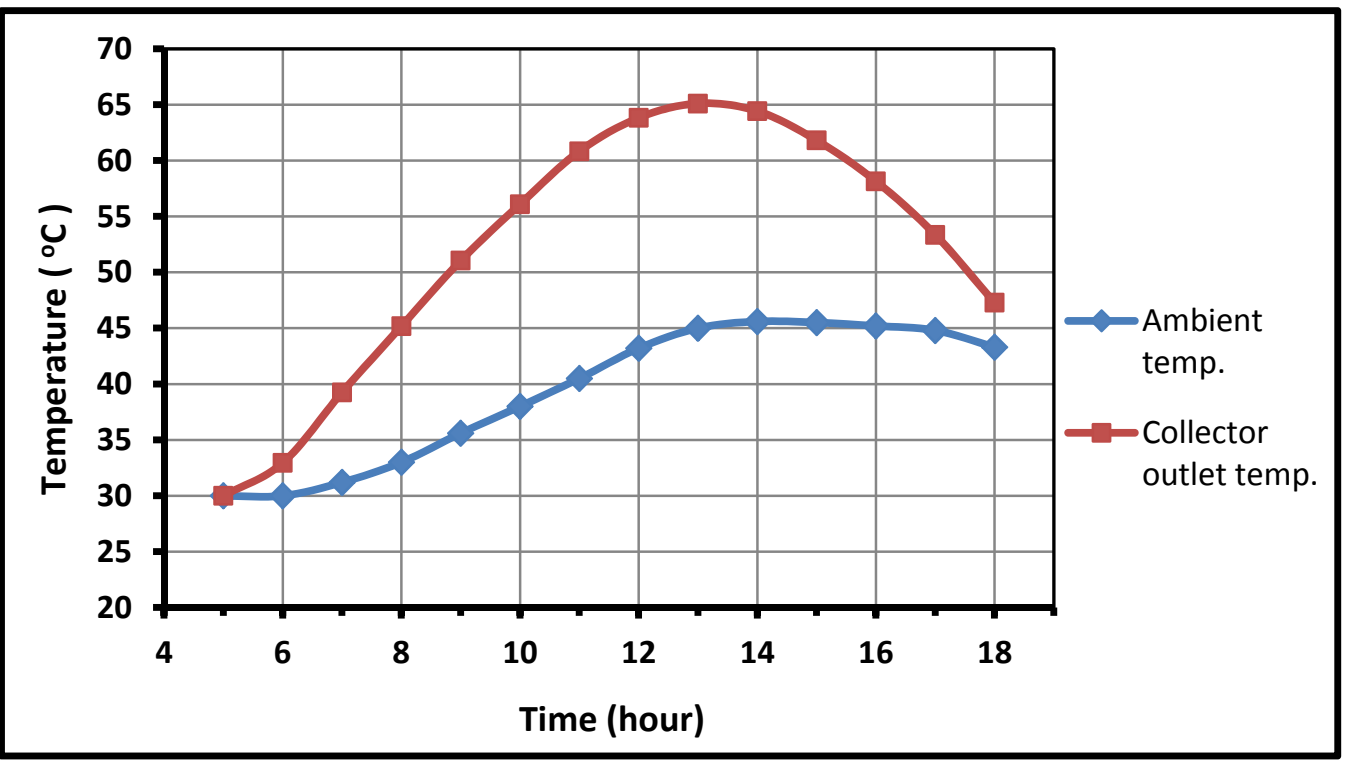

Figure 7. The collector outlet temperature and ambient temperature during 3rd of August

The solar tower performance according to Manzanares model was studies in this research; the results were shown in Figure 8 during the clear sky sun shine on 1st of January.

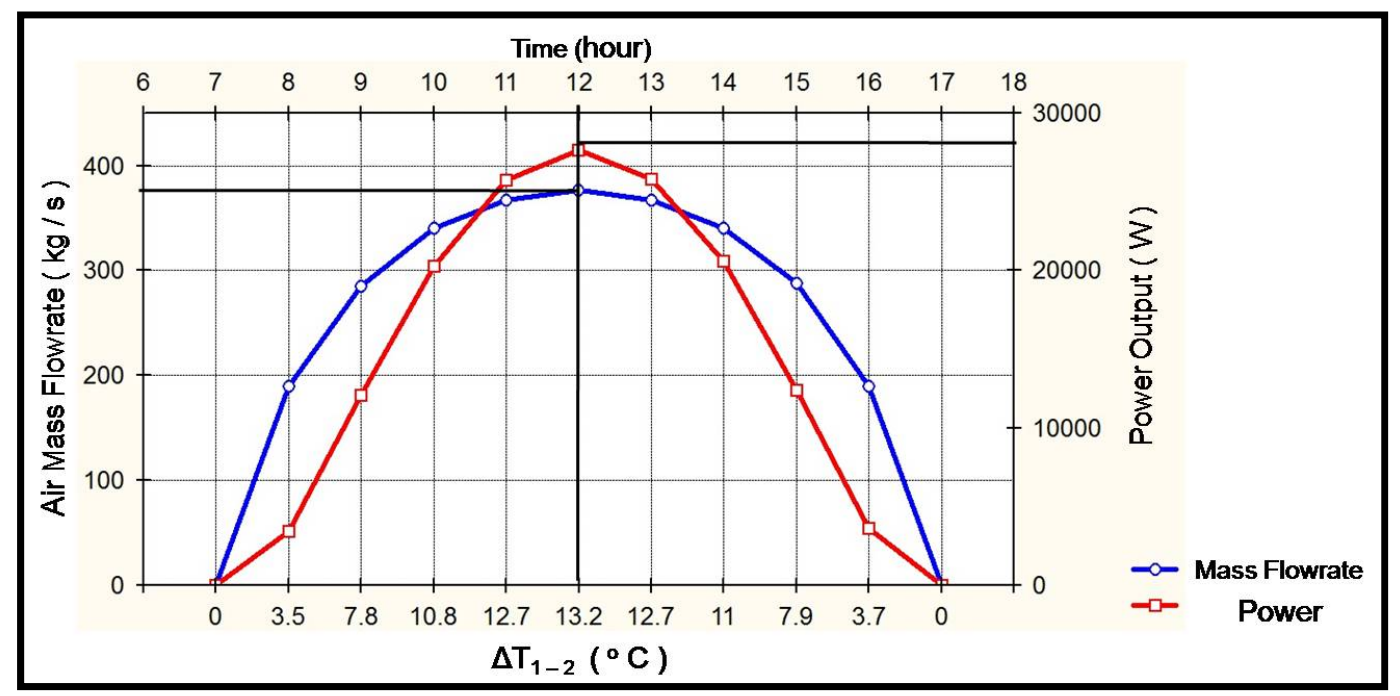

Figure 8. The solar tower performance during 1st of January for Manzanares model

To understand the effects of the solar tower configuration on its performance, the main dimensions were changed to see how the performance will change accordingly.

To do this, we have changed one of the main dimensions of the solar tower and kept the others fixed and a comparison was done for the differences of the obtained results.

It was seen from Figure 9 when the chimney height changed from 195 meter to 300 meter, the performance of the solar tower was changed, first of all the air mass flow $m$ was increased and logically the collector outlet temperature $T_{f}$ was decreased, but if we look to Equation 11, it is clear observed that the chimney velocity is a 
function of both the temperature rise $\Delta T_{I 2}$ and the chimney height $H$, but the chimney height has the major impact on chimney velocity to compensate with excess the decreasing in temperature rise.

Also, it was noticed that the power output $P$ of the solar tower was increased when the chimney height is increased. Comparing the results for both Figures 8 and 9, we found that the maximum air mass flowrate was increased from $390 \mathrm{~kg} / \mathrm{s}$ to about $430 \mathrm{~kg} / \mathrm{s}$, the temperature rise was decreased from $13.2^{\circ} \mathrm{C}$ to $11.8{ }^{\circ} \mathrm{C}$ and the power output was increased from $27000 \mathrm{~W}$ to about $42500 \mathrm{~W}$.

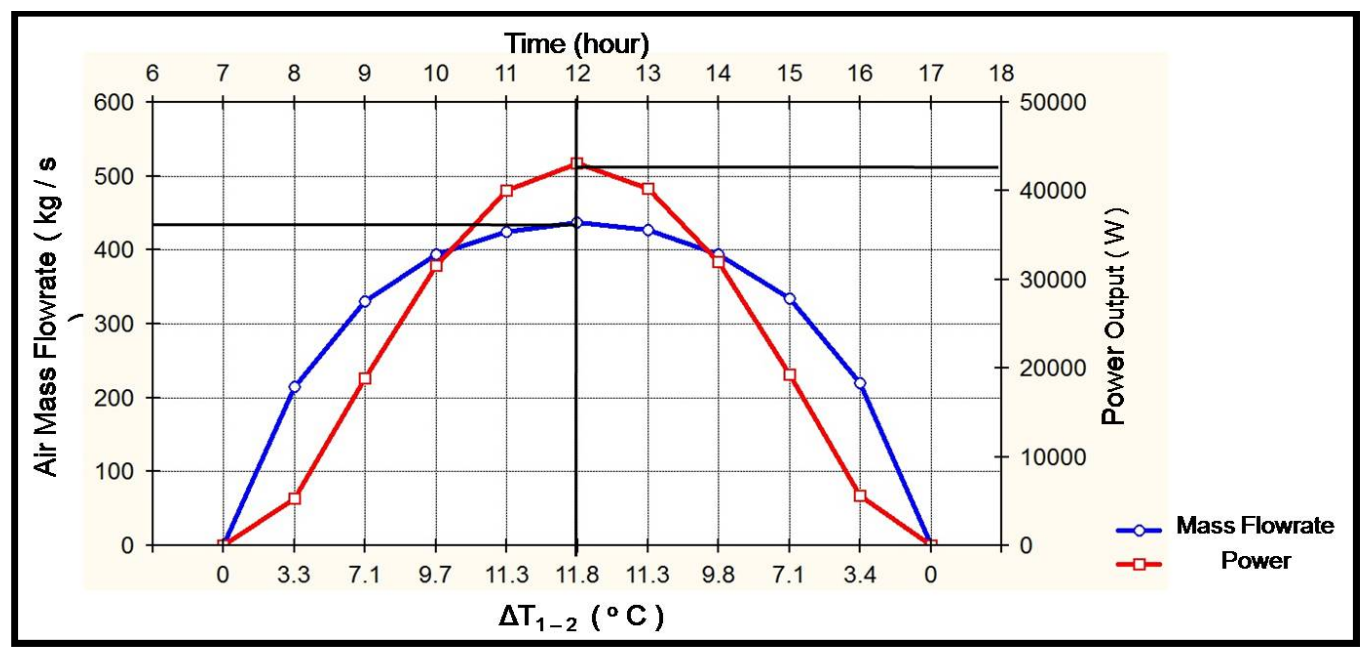

Figure 9. The solar tower performance during 1st of January when the chimney height changes from 195 meter to 300 meter and keeping other dimensions fixed for Manzanares model

Changing the collector radius $R$ was also performed in order to recognize its effect on the solar tower performance. Figure 10 shows that when the collector radius changed from 122 meter to 150 meter, the collector outlet temperature $T_{f}$ was increased according to Equation 8, which it indicates that the collector outlet temperature is a function of solar intensity $I$ and as well to collector's radius $R$, thus as the collector outlet temperature increases, it yields as a result to increase the temperature rise $\Delta T_{12}$ then the chimney velocity $V_{2}$ is increased according to Equation 11, which means increasing in air mass flowratem. Comparing the results for Figures 8 and 10, we found that the maximum air mass flowrate was increased from $390 \mathrm{~kg} / \mathrm{s}$ to about $490 \mathrm{~kg} / \mathrm{s}$, the temperature rise was increased from $13.2{ }^{\circ} \mathrm{C}$ to $21.8^{\circ} \mathrm{C}$ and the power output was increased from $27000 \mathrm{~W}$ to about $60000 \mathrm{~W}$.

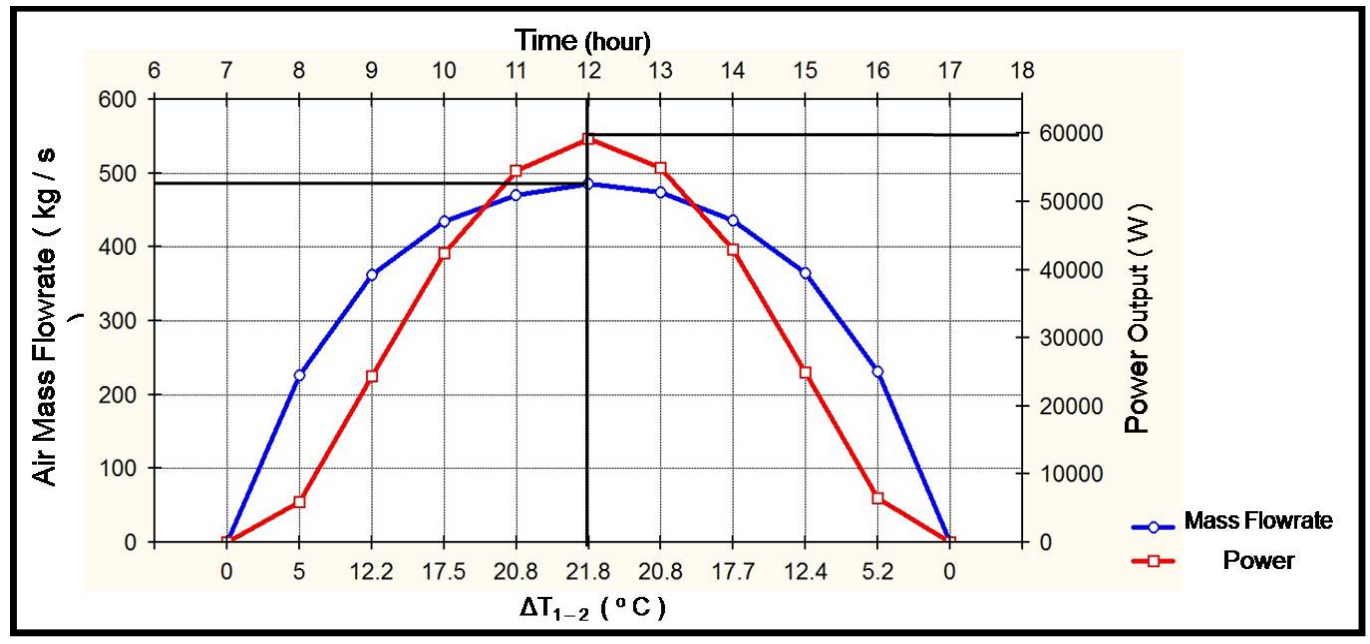

Figure 10. The solar tower performance during 1st of January when the collector radius changes from 122 meter to 150 meter and keeping other dimensions fixed for Manzanares model 
The last configuration item of the solar tower to be changed and studying it effect on the solar tower performance is the chimney diameter D. Figure 11 shows that when the chimney's diameter changed from 10 meter to 20 meter, the air mass flowrate $m$ is extremely increased inside the chimney as a result of increasing in chimney's cross - section area, this increasing in air mass flowrate causing quite decreasing in temperature rise $\Delta T_{12}$ which led to decrease in chimney's velocity $V_{2}$, so the power is not consequently extremely increases as the extremely increasing in air mass flowrate.

Comparing the results for Figures 8 and 11, we found that the maximum air mass flowrate was increased from $390 \mathrm{~kg} / \mathrm{s}$ to about $960 \mathrm{~kg} / \mathrm{s}$, the temperature rise was decreased from $13.2{ }^{\circ} \mathrm{C}$ to $5.8{ }^{\circ} \mathrm{C}$ and the power output was increased from $27000 \mathrm{~W}$ to about $31500 \mathrm{~W}$.

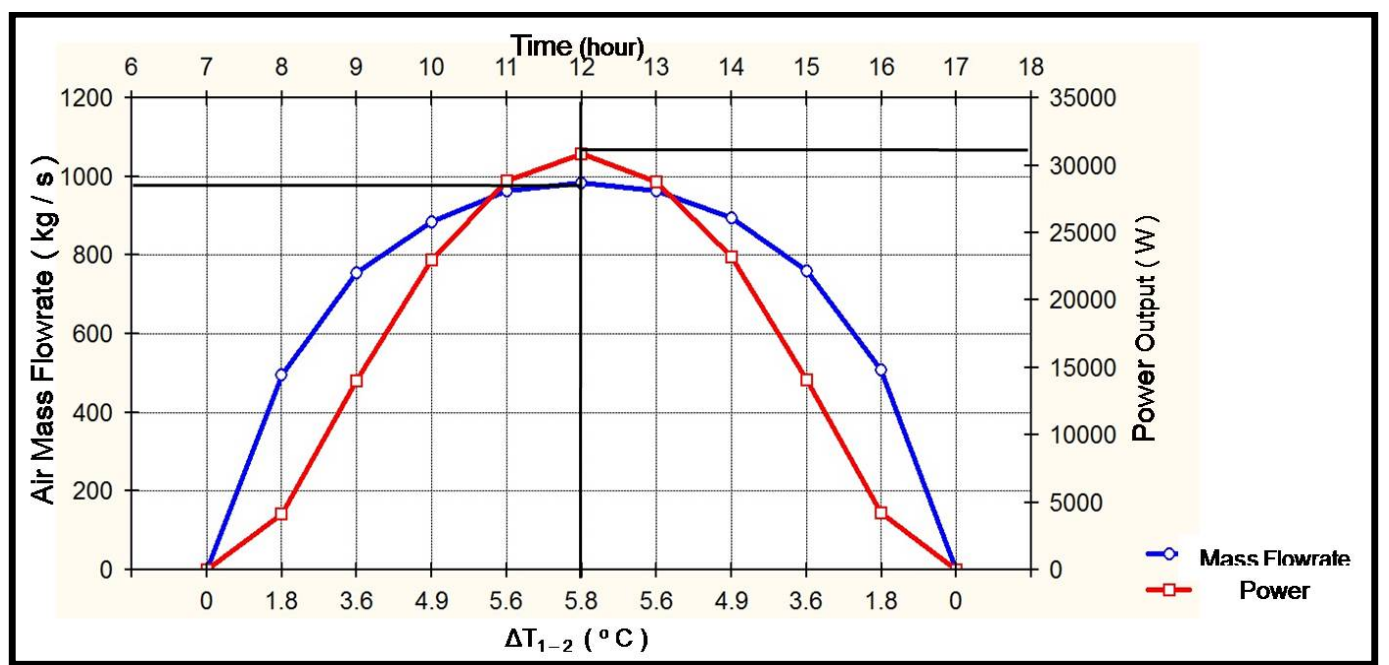

Figure 11. The solar tower performance during 1st of January when the chimney diameter changes from 10 meter) to 20 meter and keeping other dimensions fixed for Manzanares model

\section{Conclusion}

The following conclusions were attained from the foregoing model and design:

- The collector's outlet temperature is a function of the collector's area and the solar radiation; it increases as the collector's diameter and solar radiation increasing.

- The major impact on solar tower power output is obtained when the collector's diameter is increased due to increasing in collector's outlet temperature which can be considered as the driving force to increase the air flowrate velocity inside the chimney.

- The moderate impact on solar tower power output is obtained when the chimney's height is increased, this point leads to an increasing in air mass flow rate through the chimney but on contrary the temperature difference is lowered as a result of increasing in air mass flowrate.

- The lower effect on solar tower output is obtained when the chimney's diameter is increased, which causes an increase in air mass flowrate inside the chimney due to increasing in chimney's cross sectional area but lowering the temperature difference between the outlet and inlet temperature of the collector, thus lowering the air velocity inside the chimney.

- At partial load, the storage tank temperature and a wider period of useful solar time are increased, so, the solar fraction is also increased. It looks like increasing number of solar collectors.

- The collector's outlet temperature and the storage tank temperature are a function of solar intensity; they increase as the solar intensity increases.

\section{References}

Annaratone, D. (2010). Engineering Heat Transfer. New York: Springer. http://dx.doi.org/10.1007/978-3-642-03932-4

Bahrami, M. (2011). ENSC 388 Engineerimg Thermodynamics and Heat Transfer - Natural Convection Heat Transfer. Retrieved from http://www.sfu.ca/ mbahrami/ensc388.html 
Bernardes, M. A. dos S., VoB, A., \& Weinrebe, G. (2003). Thermal and Technical analysis of Solar Chimney. Solar Energy, 75(6), 511-524. http://dx.doi.org/10.1016/j.solener.2003.09.012

Bilgen, E., \& Rheault, J. (2005). Solar chimney power plant for high latitudes. Solar Energy, 79(5), 449-458. http://dx.doi.org/10.1016/j.solener.2005.01.003

Cervone, A., Romito, D. Z., \& Santini, E. (2011). Design of Solar Chimney power plant for Mediterrnean countries. International Conference on Clean Electrical Power (ICCEP), pp. 480-484. http://dx.doi.org/10.1109/ICCEP.2011.6036295

Chaichan, M. T., \& Kazem, H. A. (2011). Thermal Storage Comparison for Variable Basement kinds of a Solar Chimney Prototype in Baghdad-Iraq Weathers. International Journal of Applied Sciences, 2(2). Retrieved from http://www.cscjournals.org/csc/manuscript/Journals/IJAS/volume2/Issue2/IJAS-33.pdf

Chergui, T., Larbi, S., \& Bougdjar, A. (2011). Modelling and Simulation of Solar Chimney Power Plant Performances in Southern Region of Algeria. 2011 4th International Conference on Modeling, Simulation and Applied Optimization (ICMSAO), pp. 1-5. http://dx.doi.org/10.1109/ICMSAO.2011.5775509

Direcksataporn, B. (2008). Potential Study of Solar Chimney Power Plant in Northeastern Region of Thailand, Technology and Innovation for Sustainable Development Conference (TISD 2008), Faculty of Engineering KhonKaen University, Thailand (28 -29 January 2008).

Hamdan, M. O. (2011). Analysis of a Solar Chimney Power Plant in the Arabian Gulf region. Renewable Energy, 36(10), 2593-2598. http://dx.doi.org/10.1016/j.renene.2010.05.002

Jr.Wylie, C. R. (1966). Advanced Engineering Mathematics (3rd ed.). New York: McGraw-Hill Book Company.

Mehla, N., Makade, R., \& Thakur, N. S. (2011). Experimental Analysis of a Velocity Field using variable Chimney diameter for Solar Updraft Tower. International Journal of Engineering Science and Technology, 3(4). Retrieved from http://www.ijest.info/docs/IJEST11-03-04-267.pdf

Schlaich, J., Bdrgermann, R., Schiel, W., \& Weinrebe, G. (2005). Design of Commercial Solar Updraft Tower Sysyems-Utilization of Solar induced Convective Flows for Power Generation. Journal of Solar Energy Engineering-transactions of ASME, 127(1), 2005. Retrieved from http://www.uni-saarland.de/fak7/fze/AKE_Archiv/AKE2010H/AKE2010H_Vortraege/07Schlaich_Ergaenz ungen/AKE2010_07Schlaich2005_Sesign-ofCommercialAufwindKraftwerke_8p.pdf

Stine, W. B., \& Gayer, M. (2001). Power from the Sun-Chapter 2. Retrieved from http://www.powerfromthesun.net/book.html

Storage of Food in Developing Countries, Engineers without Borders. (2005). Retrieved from http://www.ewb-uk.org/system/files/Vivek+Mahadeven+Storage+of+Food+In+Developing+Countries.pdf

Zhou, X. P., Xiao, B., Liu, W. C., Guo, X. J., Yang, J. K., \& Fan, J. (2010). Comparison of classical solar chimney power system and combined solar chimney system for power generation and seawater desalination. Desalination, 250(1), 249-256. http://dx.doi.org/10.1016/j.desal.2009.03.007

Zhou, X. P., Yang, J. K., Xiao, B., Hou, G. Z., \& Shi, X. Y. (2008). Special climate around a Commercial Solar Chimney Power Plant. Journal of Engineering Energy, 134(1). http://dx.doi.org/10.1061/(ASCE)0733-9402(2008)134:1(6)

Zhou, X. P., Yang, J. K., Xiao, B., Hou, G. Z., \& Xing, F. (2008). Analysis of Chimney height for solar chimney

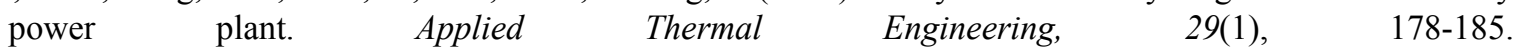
http://dx.doi.org/10.1016/j.applthermaleng.2008.02.014 